EESTI NSV TEADUSTE AKADEEMIA TOIMETISED 1954. III kd., nr. 1 ИЗВЕСТИЯ АКАДЕМИИ НАУК ЭСТОНСКОЙ ССР 1954. Том III, № 1

\title{
KARTULI SELEKTSIOONIST MADALSOODE TURVASMULDADELE
}

\section{A. KALMAN}

Vastava kuivenduse ja agrotehnika rakenáamise puhul kindlustavad Eesti NSV madalsoode turvasmullad neile rajatud kultuurniitudelt ja karjamaadelt suuri ja väärtuslikke söödasaake. Kultuurniitudelt ja karjamaadelt saadud haljassöödad ja hein aga ei rahulda veel küllaldaselt loomade söödatarvet. Seoses sellega on esile kerkinud ülesanne kasvatada soomaadel ka juur- ja mugulvilju, mis võimaldaksid saada turvasmuldadelt senisest hoopis suuremaid ja väärtuslikumaid söödasaake. Oma eriliste omaduste poolest peaks täitma seda ülesannet kõige paremini kartul.

Madalsoo turvasmulla viljakust saab agrotehniliste võtete abil kergemini tõsta kui mineraalmaa viljakust. Juba tavaliste agrotehniliste võtete rakendamise puhul on madalsoode turvasmulla lämmastikusisaldus kõrgem kui seda vajavad meie kehvade põllumuldade jaoks aretatud kartulisordid. Selle tulemuseks on kartuli kasvuaja liigselt pikaks venimine ja saakide suhteline väiksus turvasmuldadel.

Paljude aastate vältel soo-oludes teostatud sordivõrdluskatsed on näidanud, et praeguste mineraalmaa jaoks aretatud sortide (katsetati 52 kartulisorti) hulgas ei leidu turvasmuldadel kasvatamiseks kohaseid sorte. Kohaste sortide saamise ülesannet võib lahendada ainult sordiaretustööga. Et Jõgeva Riiklikus Sordiaretusjaamas soo-oludele kohaste kartulisortide aretamisega ei tegelda, siis otsustas autor 1951. aasta sügisel alustada selle ülesande lahendamist madalsoo-avamaa tingimustes, samasugustes oludes, kus edaspidi tuleb sorti kasvatada. Seemnematerjal saadi Jõgeva Riiklikult Sordiaretusjaamalt ja Oleliiduliselt Taimekasvatuse Instituudilt.

Kartul on Eesti NSV oludes ainus kultuur, mille paljundamine toimub vegetatiivselt avamaal, kuid mille selektsiooniga alustatakse tavaliselt sooja lava või kasvuhoone tingimustes. See tähendab, et sordiaretajad külvavad kartuli sortide- ja liikidevahelistest ristamistest saadud seemned, millest nad soovivad aretada avamaa põldude jaoks suuresaagilisi sorte, soojadesse lavadesse või kastidesse kasvuhoones ja sunnivad ristandeid võrdlemisi pika aja vältel arenema kasvutingimustes, mis suuresti erinevad avamaa tootmisoludele vastavatest kasvutingimustest. Kasvuhoone tingimustes tugevaks arenenud värrad istutatakse avamaale tootmistingimustesse, mis peab muutma paari kuu vanused kunstlikes oludes arenenud värrad avamaa välioludele vastupidavaks ja suuresaagiliseks sordiks. Kui arvestada seda, et kartuli istikute väljaistutamine toimub tavaliselt juuni esimese dekaadi lõpul ja et pärast väljaistutamist põeb kartulitaim juurte vigastuste ning uute olude tôttu umbes $10-20$ päeva, siis jätab niisugune aretussüsteem kartulivärdade arenemiseks avamaa tingimustes ainult umbes niisama palju aega, kui kulus kasvuhoones, ega võimalda kartuli- 
värdade küllaldast väljaarenemist vastavalt välitingimustele. Neil kaalutlustel külvati kartuli kultuursortide nii liigisisestest kui ka metsikute liikidega ristlusest saadud seemned 1951. aasta novembri alguses madalsooavamaa tingimustesse, et harjutada seemikuid idanemise algusest peale kohanema madalsoo turvasmulla omadustega ja suurte ööpäevaste temperatuurikõikumistega. Samaaegselt külvati samadesse kasvutingimustesse ristamata Solanum demissum'i, S. Schreiteri, S. depexum'i ja S. punae seemned.

1952. aasta kevadel tärkasid kõige esimestena - alates 12. maist S. Schreiteri seemikud, kuid öökülmad 16., 17. ja 18. mail (vastavalt $-9^{\circ}$, $-8,8^{\circ} \mathrm{ja}-7,1^{\circ} \mathrm{C}$ ) hävitasid kõik tärganud taimed.

S. tuberosum'i sortide- ja liikidevahelised ristandid ning metsikud ristamata S. demissum'i, S. depexum'i, S. punae ja tärkamata S. Schreiteri seemikud tärkasid enam-vähem üheaegselt 3.-10. juunini madalsoos öökülmade esinemise perioodil. Öökülmade esinemist ajavahemikus 12. maist kuni 3. juulini 1952. aastal $2 \mathrm{~cm}$ körgusel maapinnast näitab tabel 1 (vahelejäänud kuupäevadel öökülmasid ei olnud).

Tabel 1

Ööpäevased õhutemperatuuri kõikumised madalsoos

\begin{tabular}{|c|c|c|c|c|c|c|c|c|}
\hline \multicolumn{3}{|c|}{$\mathrm{M}$ a i } & \multicolumn{3}{|c|}{$\mathrm{J}$ u u n i } & \multicolumn{3}{|c|}{$\mathrm{J}$ u u $1 \mathrm{i}$} \\
\hline $\begin{array}{l}\text { Kuu- } \\
\text { päev }\end{array}$ & $\underset{\text { (päeval) }}{\text { Maksimum }}$ & $\begin{array}{c}\text { Miinimum } \\
\text { (öösel) }\end{array}$ & $\begin{array}{l}\text { Kuul- } \\
\text { păev }\end{array}$ & $\begin{array}{c}\text { Maksimum } \\
\text { (päeval) }\end{array}$ & $\begin{array}{c}\text { Miinimum } \\
(\text { öösel) }\end{array}$ & $\begin{array}{l}\text { Kuu- } \\
\text { păev }\end{array}$ & $\begin{array}{c}\text { Maksimum } \\
\text { (päeval) }\end{array}$ & $\begin{array}{c}\text { Miinimum } \\
\text { (öösel) }\end{array}$ \\
\hline $\begin{array}{l}12 \\
13 \\
16 \\
17 \\
18 \\
20 \\
21 \\
22 \\
24 \\
25 \\
26 \\
29 \\
31\end{array}$ & $\begin{array}{l}31,9 \\
33,3 \\
26,6 \\
30,4 \\
15,7 \\
24,6 \\
25,0 \\
23,4 \\
31,7 \\
34,0 \\
30,8 \\
18,4 \\
27,1\end{array}$ & $\begin{array}{l}-3,1 \\
-3,3 \\
-9,0 \\
-8,8 \\
-7,1 \\
-1,3 \\
-2,5 \\
-0,6 \\
-1,4 \\
-3,6 \\
-0,5 \\
-1,6 \\
-1,5\end{array}$ & $\begin{array}{r}1 \\
2 \\
5 \\
6 \\
7 \\
10 \\
11 \\
12 \\
13 \\
14 \\
18 \\
19 \\
26 \\
27\end{array}$ & $\begin{array}{l}31,3 \\
29,6 \\
35,5 \\
36,6 \\
30,4 \\
32,2 \\
29,7 \\
34,5 \\
37,3 \\
37,0 \\
34,7 \\
30,3 \\
28,4 \\
24,3\end{array}$ & $\begin{array}{l}-4,6 \\
-1,9 \\
-1,6 \\
-2,4 \\
-2,1 \\
-3,0 \\
-4,0 \\
-1,9 \\
-3,1 \\
-1,4 \\
-1,4 \\
-1,9 \\
-0,3 \\
-0,7\end{array}$ & $\begin{array}{l}2 \\
3\end{array}$ & $\begin{array}{l}31,6 \\
37,1\end{array}$ & $\begin{array}{l}-3,1 \\
-0,3\end{array}$ \\
\hline
\end{tabular}

S. tuberosum'i kultuursortide vahelisest ja sortide metsikute liikidega ristamisest saadud seemikud talusid õhutemperatuuri kõikumisi võrdlemisi ühtlaselt, vaatamata ristamise kombinatsioonidele. Osa tärganud seemikuid hävines juba $-2,0^{\circ} \mathrm{C}$ juures, umbes pooled neist aga säilisid $-4,0^{\circ} \mathrm{C}$ juures. Tärganud metsikute kartuliliikide seemikuid hävines samuti, kuigi vähemal arvul kui S. tuberosum'i seemikuid. Seejuures ei osutunud S. Schreiteri, S. depexum'i ja S. punae seemikud külmakindlamateks kui S. demissum'i seemikud.

Ristamisest saadud seemikud arenesid soo-oludes kasvuperioodil (juuniaugust) elujõulisteks taimedeks, mis andsid säilivaid mugulaid. Neist valiti 218 kõrgemasaagilist pesa (umbes $80 \%$ kogu öökülmadest rikkumata jäänud seemikute arvust).

1953. aasta kevadel pandi 14 . ja 15. mail kõik ületalve säilinud pesad (arvult 212) vaatamata mugulate suurusele soosse kloonide viisi vagudesse maha, vahedega $40 \times 66 \mathrm{~cm}$. Peab mainima, et soo-olud ei olnud liiga kõrge põhjaveeseisu tõttu kartuli kasvatamiseks kuigi soodsad. Vaatlusi tehti algul üks kord iga dekaadi vältel ja 1. augustist alates kuni pealsete külmumiseni iga vile päeva järel. Augustis puhastati selektsioonipinnalt hòolega välja kõik kidumishaiged ja kahtlased taimed. 
Suurem öökülm $\left(-4,2^{\circ} \mathrm{C}\right)$ esines 7 . septembril ja hävitas kõik seni säilinud pealsed. Kartuli koristamine, pesade kaalumine ja hindamine toimus 13. -15. septembril; tärklise sisaldust mugulates määrati 27.-29. septembril.

Kiirema kasvuga, varavalminud ja lehemädanikukindlamad värrad andsid suurema tärklisesisaldusega mugulaid. Kloonides hinnati iga pesa eraldi, sest ühe ja sama seemiku järglaste hulgas esines kloonis suuri erinevusi pesade saagirohkuse ja mugulate tärklisesisalduse alal.

Märkimisväärseid tulemusi andsid ristluskombinatsioonid, mis on toodud tabelis 2 (valitud kõige paremad pesad).

Parimate ristluskombinatsioonide tulemusi

Tabel 2

\begin{tabular}{|c|c|c|c|c|}
\hline Ristluskombinatsioon & $\begin{array}{c}\text { Klooni } \\
\text { nr. }\end{array}$ & $\begin{array}{c}\text { Pesa } \\
\text { nr. }\end{array}$ & $\begin{array}{c}\text { Mugulaid } \\
\text { pesas } \\
\text { kg }\end{array}$ & $\begin{array}{c}\text { Tärklise- } \\
\text { sisaldus } \\
\%\end{array}$ \\
\hline Erika $($ ( $) \times$ Frühnudel $\left(\sigma^{\star}\right)^{1}$ & $\begin{array}{r}1 \\
2 \\
7 \\
7 \\
10 \\
19\end{array}$ & $\begin{array}{r}3 \\
4 \\
5 \\
6 \\
15 \\
20 \\
25\end{array}$ & $\begin{array}{l}2,1 \\
3,0 \\
2,4 \\
1,9 \\
2,0 \\
2,0 \\
1,6\end{array}$ & $\begin{array}{l}17,2 \\
18,2 \\
17,9 \\
15,4 \\
15,9 \\
15,7 \\
17,2\end{array}$ \\
\hline Virulane $\left(\right.$ (q) $\times$ Erika $\left(\delta^{7}\right)^{2}$ & $\begin{array}{l}24 \\
26 \\
38 \\
40\end{array}$ & $\begin{array}{l}31 \\
32 \\
41 \\
45 \\
46\end{array}$ & $\begin{array}{l}2,9 \\
1,4 \\
1,8 \\
3,7 \\
1,6\end{array}$ & $\begin{array}{l}16,6 \\
17,3 \\
16,3 \\
15,4 \\
16,4\end{array}$ \\
\hline Ostbote $(\%) \times$ Frühnudel $\left(\delta^{\prime}\right)^{3}$ & $\begin{array}{r}97 \\
98 \\
100\end{array}$ & $\begin{array}{l}84 \\
85 \\
88\end{array}$ & $\begin{array}{l}1,7 \\
2,3 \\
1,6\end{array}$ & $\begin{array}{l}17,1 \\
16,0 \\
16,9\end{array}$ \\
\hline starkeragis $(7) \times$ S. demissum $\left(\sigma^{\prime \prime}\right)^{4}$ & $\begin{array}{l}106 \\
109 \\
111\end{array}$ & $\begin{array}{r}95 \\
99 \\
104\end{array}$ & $\begin{array}{l}1,7 \\
1,7 \\
1,4\end{array}$ & $\begin{array}{l}17,4 \\
16,3 \\
17,1\end{array}$ \\
\hline & $\begin{array}{l}207 \\
209 \\
210 \\
\\
212 \\
213 \\
224 \\
\\
130\end{array}$ & $\begin{array}{l}122 \\
124 \\
126 \\
129 \\
130 \\
131 \\
134 \\
143 \\
147 \\
145 \\
165\end{array}$ & $\begin{array}{l}1,4 \\
1,9 \\
1,5 \\
1,4 \\
1,4 \\
2,1 \\
2,0 \\
3,0 \\
2,1 \\
2,5 \\
2,3\end{array}$ & $\begin{array}{l}16,3 \\
15,8 \\
17,9 \\
15,2 \\
15,1 \\
15,3 \\
15,6 \\
16,0 \\
20,5 \\
15,3 \\
17,7\end{array}$ \\
\hline
\end{tabular}

I See kombinatsioon andis enamiku vōrdlemisi lehemädanikukindlaid taimi.

2 Virulane oli lehemädanikuõrn, Erika lehemädanikukindel. Värdadel esines lehemädanikukindluse suhtes suuri erinevusi kloonide vahel ja väiksemal määral ka kloonides. Enamik kloone sisaldasid siiski lehemädanikuõrnu taimi, mille pealsed kadusid varakult ja mis seetõttu välja praagiti.

${ }_{3}$ See kombinatsioon andis enamikus väikeste mugulatega, tagasihoidliku saagiga ${ }^{\prime}$ ja väikese tärklisesisaldusega lehemädanikuõrnu järglasi, kuid leidus ka lehemädanikukindlaid kloone.

4 See kombinatsioon andis väga mitmesuguste omadustega järglasi.

5 Vastupidise ristluskombinatsiooni (1040-45 (ㅇ) $\times 683-44$ (ㅅ) 22-st kloonist ei saadud ühtegi tähelepanuväärivat järglast. 
Enamik viimase ristluskombinatsiooni pesadest olid sedavõrd head, et nad võiksid olla suuresaagiliste ja lehemädanikukindlate kartulisortide aretamise aluseks.

Värd 683-44 on saadud Virulase (ํ) ja Münchebergi ir. 40663/21 ( $\left.\sigma^{7}\right)$ ristlusest; viimase täpne ristluskombinatsioon on autorile teadmata, kuid S. demissum'i osavõtt kombinatsioonist on kindel. Värd nr. 1040-45 on saadud Priekuli Klara (q) ja Katahdini $\left(\sigma^{7}\right)$ ristlusest.

Mineraalmuldadega võrreldes on soomuldadel kasvatatud kartuli tärklisesisaldus suure mugulasaagi puhul tavaliselt madalam. Sel põhjusel valiti edasiseks paljundamiseks ja hindamiseks pesad, kus mugulaid oli $1,0-3,7 \mathrm{~kg}$ ning tärklise sisaldus mugulates $15 \%$ ja üle selle. Selliseid pesasid leidus 54 ja nad omasid kõik lehemädanikule vastupidavaid pealseid. Lehemädanikule vastupidavate pealsetega pesades olid mugulad puhtad ka mustkärntõvest.

Uheaegselt sordiaretuskatsetega madalsoos teostatud sordivõrdluskatses, kus kuivendustingimused olid paremad selektsiooniväljaku kuivendustingimustest ja kasvutingimused kartulile kõigiți soodsamad, jäid kartulisaagid 1953. aastal madalateks. Sordivordluskatse tulemused on toodud tabelis 3.

Tabel 3

1953. aastal madalsool teostatud kümne kartulisordi vōrdluskatse tulemused

\begin{tabular}{l|c|c|c}
\hline \multicolumn{1}{c|}{ Sordi nimetus } & $\begin{array}{c}\text { Pésa kesk- } \\
\text { mine kal } \\
\text { kg }\end{array}$ & $\begin{array}{c}\text { Tärklise- } \\
\text { sisaldus } \\
\%\end{array}$ & $\begin{array}{c}\text { Mugulasaak } \\
\text { ha kohta } \\
\text { ts }\end{array}$ \\
\hline Priekuli varajane & 0,51 & 8,2 & 256 \\
Suvik & 0,45 & 11,9 & 229 \\
Virulane & 0,46 & 13,7 & 235 \\
Brigadir & 0,37 & 8,1 & 183 \\
Kalev & 0,36 & 9,4 & 161 \\
Erdgold & 0,46 & 12,1 & 232 \\
Ostbote & 0,40 & 13,5 & 206 \\
Dr. J. Aamisepp & 0,34 & 13,4 & 176 \\
Sangar & 0,53 & 14,0 & 281 \\
Olev & 0,40 & 16,0 & 201 \\
& & &
\end{tabular}

Vähese tärklisesisaldusega madala mugulasaagi põhjustas 1953. aasta sordivõrdluskatses varasemate kartulisortide pealsete enneaegne hävinemine lehemädaniku tagajärjel ning hilisematel sortidel liigselt aeglane mugulate moodustumine soo-oludes. Samadel põhjustel olid ka mujal soooludes kartulisaagid 1953. aastal väikesed.

Sordivõrdluskatse andmete kõrvutamine soo-avamaa tingimustes aretusest saadud parimate kartulipesade suurte mugulasaakidega näitab, kuivõrd suurt tähtsust omab soo-oludele kohasemate sortide aretamine.

Värdade saagikuse suhtes saab täielikuma pildi teise ja kolmanda paljunduse järel, s. o. 1954. ja 1955. aasta sügiseks, sest 1953. aasta esimese paljunduse puhul maha pandud paljud pähklisuurused mugulad ja puudulikult kuivendatud turvasmuld ei kindlustanud veel täit saaki, ja nagu kartuli sordiaretuse praktika mineraalmaal lubab arvata, võivad mugulasaagid edaspidi veelgi tõusta.

Kui võrrelda kartuli sordiaretuse esimesi soo-oludes saadud tulemusi teiste sordiaretusasutuste tulemustega, siis paistab silma soo-avamaa kartuliselektsioonist saadud kõrge tärklisesisaldusega ja võrdlemisi suuresaagiliste pesade suhteline rohkus. See on seletatav ristandite võimega kohaneda kasvutingimustele. 
Kartuliseemnete sügisene avamaale külvamine kui aretusvõte vajab edasist kontrollimist. Selge on, et seda võtet on võimalik kasutada. 1953. aasta kevadel (24. aprillil) soo-avamaale külvatud kartuliseemned idanesid ja arenesid samuti hästi. Võib-olla, et soos teostatud varakevadised kartuliseemne külvid annavad samu tulemusi kui sügisesed külvid. Uksikutel juhtudel, kui on karta, et temperatuur võib soos pärast taimede tärkamist langeda alla $-4^{\circ} \mathrm{C}$, tuleb taimi katta, et vältida noorte kartulitaimede enamiku hävingut, millega võib kaotsi minna osa väärtuslikest värdadest.

Aretustöö esialgsed tulemused kinnitavad, et ilma seemikute eelneva aretamiseta lavades või kasvuhoonetes ja seemikute ühest paigast teise istutamiseta on võimalik soo-avamaal edukalt kartulisorte aretada, sest madalsoo karmide, kuid pidevalt toiteküllaste kasvutingimuste mõjul arenevad seemikud kohasemaks soo taimekasvutingimustele. Samaaegselt toimub seal karm looduslik valik suurte öö-päevaste õhutemperatuuri kõikumiste näol, lülitades välja kõik taimed, mis ei suuda kohaneda madalsoo karmidele taimekasvutingimustele. Esialgsed töötulemused näitavad seega, et värdade osaline väljalangemine öökülmade môjul ei piira soo-oludele kohaste kõrge saagikusega kartulisortide aretamist, vaid just vastupidi, et soo-oludele kohaneda suutnud värdade hulgas leidub rohkesti ristandeid, milledest on võimalik saada suuretoodangulisi sorte.

\title{
О СЕЛЕКЦИИ КАРТОФЕЛЯ ДЛЯ ТОРФЯНЫХ ПОЧВ НИЗИНнЫХ БОЛОТ
}

\author{
А. А. КАЛЬМАН
}

Резюме

Результаты многолетних работ по сортоиспытанию картофеля на торфяных почвах низинных болот показали, что количество доступного растениям азота в этих почвах во много раз выше, чем сорта могут продуктивно использовать в условиях болота. Вследствие этого на плодородных торфяных почвах низинных болот нарушается режим питания растений, невыгодно удлиняется вегетационный период картофеля и урожай клубней бывает посредственным. Собранные материалы убедительно показывают, что только сорта, приспособленные к почвенно-климатическим условиям низинных бслот, могут в этих условиях давать высокие урожаи.

Это заставило автора приступить к выведению высокоурожайных и фитофтороустойчивых сортов картофеля, приспособленных к выращиванию на осушенных болотах.

Полученные от Йгеваской государственной селекционной станции и Всесоюзного института растениеводства семена от внутри- и межвидовых скрещиваний картофеля были высеяны в открытый грунт на осушенном болоте в ноябре 1951 года.

Весной 1952 года в период развития всходов наблюдались частые ночные sаморозки, причем температура падала в отдельных случаях до $-4,0^{\circ}$ C. В этих условиях часть всходов погибла уже при $-2,0^{\circ} \mathrm{C}$, а другая часть, выдержавшая заморозки, развивалась нормально и дала к осени клубни. В ходе уборки урожая осенью 1952 года было отобрано 218 растений (около 80\% общего количества растений, выдержавших заморозки). 
Клубни отобранных растений хорошо перенесли зимовку, и 212 сохранившихся клонов были высажены на низинном осушенном болоте весной 1953 года.

Осенью 1953 года, после детальной и строгой выбраковки растений с признаками заболеваний и неустойчивых против фитофторы, было отобрано 54 гнезда с урожайностью от 1 до 3,7 кг клубней в гнезде, с содержанием крахмала в клубнях от 15 до $20,5 \%$.

Автором эффективно использован прием посева семян в грунт, благодаря чему гибридные сеянцы с самого начала роста развивались в условиях открытого грунта, что способствует их приспособлению к условиям среды.

Институт мелиорации и освоения осушенных земель Академии наук

Поступила в редакцию Эстонской ССP 